\title{
Бактериальное выщелачивание основных сульфидных минералов медно-никелевых руд. Обзор.
}

\author{
Янишевская Е.С. ${ }^{1}$, Горячев А.А. ${ }^{2}$ \\ ${ }^{1}$ ИППЭС ФИЦ КНЦ РАН, Anamumbl, drygina_es@mail.ru \\ ${ }^{2}$ ПТТБА КНЦ РАН, Anamumbl, andrej.goria4ev@yandex.ru
}

Аннотация. В статье рассмотрены особенности бактериального выщелачивания основных сульфидных минералов месторождений медно-никелевых руд Мурманской области. Сделан акцент на вклад бактерий в темпы извлечения меди и никеля в процессе выщелачивания. Отмечено, что растворение пентландита протекает наиболее эффективно при использовании штамма Acidothiobacillus ferrooxidans. Особенность растворения халькопирита заключается в образовании пассивирующего слоя, в особенности - ярозита. Окисление пирротина сопровождается выделением значительного количества тепла, что необходимо учитывать при проектировании технологических схем кучного выщелачивания в климатических условиях северных регионов, так как это поможет предотвратить замерзание раствора и увеличить интенсивность перехода металлов в раствор.

Ключевые слова: гидрометаллургия, биовыщелачивание, сульфидные руды, цветные металлы, пентландит, халькопирит, пирротин.

\section{Bioleaching of major sulfide minerals of copper-nickel ores. A review.}

Yanishevskya E.S., ${ }^{1}$ Goryachev A.A. ${ }^{2}$

${ }^{1}$ INEP KSC RAS, Apatity,drygina_es@mail.ru

${ }^{2}$ NTTSA KSC RAS, Apatity, andrej.goria4ev@yandex.ru

Abstract. Biohydrometallurgy, which exploits microbiological processes to recover metal ions, is regarded as one of the most promising and revolutionary biotechnologies. This review outlines previous and current research in bioleaching processes, particularly in respect of the biooxidation of pentlandite, chalcopyrite and pyrrhotite. The oxidation of these minerals is reviewed with emphasis on the contribution from the microbial community, specifically direct and indirect contact of bacteria with the mineral surface. The bacterial leaching behavior of copper and nickel from a low-grade sulfide ore was investigated. The main reason for the slow rate of chalcopyrite dissolution is the formation of a layer on the surface of the mineral that hinders dissolution, termed "passivation". pyrrhotite.

Key words: hydrometallurgy, bioleaching, sulfide ores, non-ferrous metals, pentlandite, chalcopyrite,

\section{Введение}

Основную промышленную ценность имеют медно-никелевые месторождения магматического генезиса. Наиболее распространены месторождения сульфидного медно-никелевого типа, связанные с магматическими телами базитового и гипербазитового состава. В целом, сульфидные медно-никелевые месторождения характеризуются выдержанностью минерального состава руд. Главными рудными минералами являются пирротин, магнетит, пентландит и халькопирит. Помимо них в рудах зачастую встречаются пирит, кубанит, никелин, миллерит, виоларит, минералы группы платины, присутствуют также хромит, арсениды никеля и кобальта, самородное золото, иногда галенит, сфалерит, борнит, макинавит, валлериит (Игревская, 2009). Вследствие этого, помимо цветных металлов и железа, руды в качестве примесей могут содержать металлы платиновой группы, драгоценные металлы, молибден и др. Среднее содержание меди и никеля в рудах колеблется от долей до первых процентов.

В переработке сульфидного сырья главную роль играют пирометаллургические методы, к которым относятся окислительный обжиг, электроплавка, производство файнштейнов (Чижиков и др., 1962). Гидрометаллургические технологии применяются, главным образом, на стадии рафинирования металлов. Однако гидрометаллургия привлекает все большее внимание, исследования на- 
правлены на реализацию возможности переработки медно-никелевого сырья без применения пирометаллургии (Brierley, Brierley, 2001). В особенности уделяется внимание методам выщелачивания сульфидных руд. Наиболее часто применяемыми разновидностями выщелачивания являются кучное, чановое, подземное и автоклавное. Каждый из этих методов имеет значительные перспективы, связанные, в первую очередь, с высокой степенью извлечения как главных, так и второстепенных металлов из руд (до 90-95 \% и более), что особенно важно в случае переработки тонко-вкрапленных руд.

Все большую актуальность приобретает поиск экономически и экологически обоснованных способов извлечения цветных металлов из бедных руд и техногенного сырья. Это, главным образом, связано с тем, что качество поступающих на обогащение руд неуклонно снижается, вызывая рост объема извлекаемых руд, ухудшая тем самым состояния природных экостистем. Вовлечение в переработку отходов обогащения для извлечения ценных металлов представляется необходимым процессом, позволяющим снизить нагрузку на окружающую среду, так как в процессе хранения горнопромышленных отходов происходят существенные изменения минерального состава, в результате чего тяжелые металлы переходят в состав водорастворимых солей, что повышает опасность их хранения.

Так как в настоящее время стоит проблема истощения запасов медно-никелевых руд, которые можно перерабатывать с помощью традиционных технологий обогащения, то ведутся разработки технологий, которые позволяют извлекать цветные металлы из бедных руд, техногенных отходов и некондиционных концентратов. Извлечение цветных металлов, содержащихся в отходах добычи, с помощью микроорганизмов представляет собой экономичную альтернативу традиционным гидрометаллургическим процессам.

Мурманская область располагает рядом объектов, для вовлечения в производство которых необходим поиск более рациональных методов переработки. К таким объектам относятся медноникелевые руды Мончеплутона, которые являются примером вышеупомянутых интрузий базитультрабазитового состава (Припачкин, 2013). Среди техногенных объектов перспективными для переработки считаются хвосты обогащения медно-никелевых руд АО «Кольская ГМК», а также Аллареченское техногенное месторождение, образованное отходами добычи сульфидных медноникелевых руд коренного Аллареченского месторождения.

\section{Микроорганизмы в биотехнологиях переработки сульфидных минералов}

В настоящее время микроорганизмы, используемые в биотехнологиях переработки сульфидных руд, достаточно хорошо изучены (Colmer, Hinkle, 1947; Rawlings, 2002; Каравайко и др., 2006; Кондратьева и др., 2015; Schippers, 2007). Наиболее важным для практического применения является Acidothiobacillus ferrooxidans - первый описанный и широко изученный микроорганизм, способный окислять двухвалентное железо и пирит (Colmer, Hinkle, 1947; Temple, Colmer, 1951). Однако сейчас показано, что в процессах биовыщелачивания преобладают и другие виды микроорганизмов. Данные микроорганизмы неоднородны с точки зрения филогении, при этом обладают общими физиологическими свойствами, такими как использование для энергетического метаболизма неорганических соединений (сера и ее восстановленные соединения, двухвалентное железо и сульфидные минералы), ацидофилия с оптимальными значениями $\mathrm{pH}$ в пределах от 1 до 2,5 и устойчивость к ионам тяжелых металлов, таким как $\mathrm{Cu}^{2+}, \mathrm{Ni}^{2+}, \mathrm{Zn}^{2+}, \mathrm{Co}^{2+}, \mathrm{Fe}^{2+}$. (Hallberg, Johnson, 2003; Baker, Banfield, 2003; Schippers et al., 2013; Donati, Sand, 2007; Colmer, Hinkle, 1947; Temple, Colmer, 1951).

\section{Биовыщелачивание пентландита}

Главным концентратором никеля в руде чаще всего выступает пентландит (Fe, $\mathrm{Ni})_{9} \mathrm{~S}_{8}$. Особенностям его растворения уделено большое внимание, как в прошлых, так и в современных исследованиях (Harlamovs et al., 2004; Giaveno, Donati, 2001; Torma, 1971; Kai et al., 1995; Semenza et al., 2002; Mason, Rice, 2002; Zhang, Fang 2005; Cameron et al., 2013). Отмечено, что использование адаптированных штаммов бактерий к концентратам приводит к более высоким извлечениям никеля (Kai et al., 1995).

Работа Garcia et al. (1997) была направлена на изучение процессов растворения основных рудных минералов. Исследуемый образец руды содержал $11 \%$ никеля, заключенного, главным обра- 
зом, в пентландите. Помимо этого образец содержал пирротин, халькопирит и кубанит $\left(\mathrm{CuFe}_{2} \mathrm{~S}_{3}\right)$. В исследовании использовались штамм At. ferrooxidans - как окислитель железа и серы, и штамм At. thiooxidans - окислитель серы. За четыре недели эксперимента было извлечено $40 \% \mathrm{Ni} \mathrm{c} \mathrm{примене-}$ нием штамма At. ferrooxidans, $230 \%$ с применением At. thiooxidans и $\sim 20 \%$ без применения бактерий. Было установлено, что с применением At. ferrooxidans пирротин окислялся полностью, тогда как пентландит, кубанит и халькопирит лишь частично, а в качестве продуктов реакции образовывались ярозит и элементарная сера. В свою очередь, применение At. thiooxidans не привело к образованию указанных продуктов, а пирротин окислялся лишь частично, тогда как халькопирит, кубанит и пентландит в значительной степени не окислялись, что привело к малому извлечению меди к концу эксперимента.

Zhang and Fang (2005) исследовали биовыщелачивание концентрата с содержанием пентландита $95 \%$ (содержание металлов: $32 \% \mathrm{Ni} ; 31 \% \mathrm{Fe} ; 32 \% \mathrm{~S}$ и $0.8 \% \mathrm{Cu}$ ), используя At. ferrooxidans и неидентифицированный термофильный штамм бактерий (MLY). Авторы пришли к выводу, что At. ferrooxidans, прикрепленные к поверхности минерала, внесли наибольший вклад в извлечение никеля. Помимо этого, было отмечено присутствие серы на поверхности пентландита после его обработки бактериальным раствором, что указывает на неспособность термофильного штамма MLY окислять серу до сульфата.

В исследовании Pagnanelli et al. (2007) было показано, что повышению скорости выщелачивания никеля способствовал рост температуры, увеличение концентрации $\mathrm{Fe}^{3+}$ и частичное замещение $\mathrm{SO}_{4}{ }^{2-}$ на $\mathrm{Cl}-$. Штамм At. ferrooxidans использовался для окисления $\mathrm{Fe}^{2+}$ до $\mathrm{Fe}^{3+}$ при $30^{\circ}$ С. Богатый ионами $\mathrm{Fe}^{3+}$ подогретый до $50^{\circ} \mathrm{C}$ раствор подавался для окисления пентландита. В результате этот процесс характеризовался непрерывным образованием $\mathrm{Fe}^{3+}$ в биореакторе и последующим высокотемпературным выщелачиванием пентландита. Используя этот метод, за 5 дней в раствор удалось извлечь $83,8 \% \mathrm{Ni}$. Согласно полученным результатам, с использованием данного подхода можно значительно улучшить процесс кучного выщелачивания.

Были проведены исследования (Li et al., 2012) по выяснению механизма разложения пентландита с помощью электрохимических измерений. Для этого использовался порошковый микроэлектрод с нанесенным на поверхность штаммом At. ferrooxidans. Результаты показали, что при низком потенциале, около - 0.2 В и частичном удалении ионов $\mathrm{Fe}$ и $\mathrm{Ni}$ из минеральной решетки пентландит превращался в промежуточную фазу $\left(\mathrm{Fe}_{4,5-\mathrm{y}} \mathrm{Ni}_{4,5-\mathrm{x}} \mathrm{S}_{8-\mathrm{z}}\right)$. При изменении потенциала с -0.2 до $0.2 \mathrm{~B}$ образуется нестабильный виоларит $\left(\mathrm{Fe}_{3} \mathrm{Ni}_{3} \mathrm{~S}_{4}\right)$. Когда потенциал становился выше 0.2 В нестабильная промежуточная фаза полностью растворялась, что сопровождалось образованием серы на поверхности минерала. Было показано, что присутствие бактерий способствовало удалению серы с минеральной поверхности при окислительно-восстановительном потенциале в диапазоне от -0.75 до -0.5 В.

\section{Биовыщелачивание халькопирита}

Oсобое внимание уделяется определению характера растворения халькопирита $\left(\mathrm{CuFeS}_{2}\right)$ вследствие того, что данный минерал является упорным (Debernardi, Carlesi, 2013) для вскрытия выщелачивающими растворами (Panda et al., 2012; Zhang, Fang, 2005; Sasaki et al., 2012; Fu et al., 2008).

Большинство исследователей сделали акцент на механизмы и факторы, определяющие скорость растворения халькопирита и предположили, что его медленное растворение объясняется образованием в процессе выщелачивания пассивирующего слоя (Pradhan et al., 2008; Watling, 2006; Klauber, 2008; Rodriguez et al., 2003; Stott et al., 2000). Образование этого слоя связывают с образованием сульфатов железа, в частности - ярозита ( $\left.\left.\mathrm{KFe}_{3}^{3+}{ }_{3} \mathrm{SO}_{4}\right]_{2}[\mathrm{OH}]_{6}\right)$ (Hackl et al., 1995). Исследования пассивирующего слоя показали, что в зависимости от физико-химических условий процесса он может количественно и качественно изменяться (Dutrizac, 1983; Vilcaez et al., 2008).

B Zhao et al. (2015) было отмечено, что в присутствии At. ferrooxidans усиливалось, главным образом, растворение железа, что приводило к переходу халькопирита в промежуточную фазу халькозин $\left(\mathrm{Cu}_{2} \mathrm{~S}\right)$. Это привело к высокой скорости извлечения меди. Однако окисление халькопирита приводит также к образованию полисульфидов $\left(\mathrm{S}_{\mathrm{n}}{ }^{2-}\right)$, что вызывает формирование пассивиру- 
ющего слоя на более поздней стадии биовыщелачивания. Было отмечено, что при использовании штамма At. thiooxidans халькопирит подвергался прямому окислению до полисульфида и ковеллина $(\mathrm{CuS})$. При этом отмечалось образование пассивирующего слоя.

Gu et al. (2014) исследовали изменения поверхностных свойств халькопирита после биовыщелачивания с применением штамма Leptospirillum ferriphilum. Результаты рентгенофазового анализа, сканирующей электронной микроскопии и анализа энергодисперсионной рентгеновской спектроскопии показали, что в процессе биовыщелачивания с L. ferriphilum поверхность халькопирита покрывалась серой и ярозитом. Основным компонентом пассивирующего слоя, который блокировал непрерывное извлечение меди, являлась сера.

\section{Биовыщелачивание пирротина}

Пирротин является типичным сульфидным минералом медно-никелевых месторождений (Veglio et al., 1995; Belzile et al., 2004). Имеет нестехиометрический состав в виде $\mathrm{Fe}_{1-\mathrm{x}} \mathrm{S}$, где х изменяется от $0(\mathrm{FeS})$ до $0,125\left(\mathrm{Fe}_{7} \mathrm{~S}_{8}\right)$. Массивные сульфидные месторождения, содержащие пирротин, находятся по всему миру, в частности - в России, Китае, Австралии и Канаде.

Исследования механизма биологического выщелачивания пирротина (Jiang et al., 2006; Veglio et al., 1995) и кинетики выщелачивания (Qiu et al., 2003; Scharer et al., 2000) находятся на предварительной стадии.

В основном, исследования растворения пирротина проводились для чанового и кучного бактериального выщелачивания (Rosenblum, Spira, 1995; van Aswegen et al., 2007; Salo-Zieman et al., 2006; Plumb et al., 2008; Williams, 2006). Так, было установлено (Watling 2008), что растворение пирротина при выщелачивании происходит с потреблением кислоты. Окисление пирротина в присутствии влаги и кислорода сопровождается выделением тепла. Теплота реакции пирротина составляет -11,373 кДж/кг минерала (van Aswegen et al., 2007), это особенно необходимо учитывать при проектировании технологических схем кучного выщелачивания в климатических условиях северных регионов, что поможет предотвратить замерзание раствора и увеличить интенсивность процесса. При исследовании пирротиновых хвостов (Garg S. et al., 2015) было отмечено, что изменение концентраций необходимых питательных веществ в среде приводит к увеличению численности At. ferroxidans, а дополнительная аэрация, контроль значений рН раствора и высокая концентрация окислителя $\mathrm{Fe}^{3+}$ в экспериментах показали более высокое извлечение никеля, в отличие от тех, где не было контроля за $\mathrm{pH}$. Кроме того, установлено, что переход сульфида в $\mathrm{S}^{0}$ выше в экспериментах с контролем $\mathrm{pH}$ и составляет $32 \%$ по сравнению с экспериментом без контроля $\mathrm{pH}-10 \%$.

Проведен ряд исследований, направленных непосредственно на изучение и интенсификацию перехода металлов в раствор при кучном выщелачивании с акцентом на растворение пирротина (Ke, Li, 2006; Santos et al., 2006; Anjum et al., 2012 и др). Li and Ke (2001) было показано преимущество адаптации штамма бактерий при биовыщелачивании богатого никелем пирротинового концентрата ( $\mathrm{Ni}-2.06 \%$, $\mathrm{Co}-0.06 \%$, S - $7.56 \%$, Fe - $20.1 \%, \mathrm{MgO}-20.7 \%$ ). С использованием адаптированного к концентрату штамма At. ferrooxidans позволило за 16 дней извлечь 91 \% Ni и 87 \% Ni с помощью неадаптированного штамма At. ferrooxidans. В контрольном опыте без бактерий в раствор перешло $22 \% \mathrm{Ni}$.

B pаботе Gu et al (2009) отмечаются изменения поверхностных свойств пирротина после контакта с Leptospirillum ferriphilum и Acidithiobacillus caldus. Наблюдалось, что степень взаимодействия пирротина с A. caldus была гораздо более выраженной, чем у L. ferriphilum, из-за разного сродства A. caldus и L. ferriphilum к пирротину. После обработки A. caldus поверхность пирротина образовала мембрану из серы, что было показано рентгенофазовым анализом и энергодисперсионной спектроскопией (EDS), это объясняет увеличение гидрофобности пирротина. Однако угол смачивания и гидрофобность поверхности пирротина, обработанного L. ferriphilum, продолжали уменьшаться во время биовыщелачивания. Железоокисляющие бактерии обеспечивают функцию опосредованного механизма биологического выщелачивания пирротина, а сероокисляющие бактерии предлагают функцию прямого механизма. 


\section{Заключение}

На сегодняшний день биотехнологии по переработке сульфидных руд используются в промышленных масштабах и распространены по всему миру. С использованием микроорганизмов в основном перерабатываются концентраты золотосодержащих руд, бедные медные руды, в которых медь находится во вторичных минералах и легко поддается окислению, никелевые и полиметаллические руды.

До недавнего времени отходы обогатительных фабрик и пиррометаллургических предприятий не представляли промышленной ценности. Снижение качества сырьевой базы приводит к тому, что отходы начинают рассматривать в качестве техногенных месторождений. Однако, вовлечение таких отходов в переработку ограничивается отсутствием подходящих технологий. Поэтому задачи по выделению из природных и техногенных систем сообществ ацидофильных хемолитотрофных микроорганизмов, изучению их состава, свойств и роли каждого из них в процессах воздействия на сульфидные минералы, а также поиски возможных способов воздействия на их скорость и эффективность не теряют свою актуальность и в данный момент.

\section{Литература}

1. Игревская Л. В. Тенденции развития никелевой промышленности: мир и Россия. -2009.

2. Каравайко Г. И., Дубинина Г. А., Кондратьева Т. Ф. Литотрофные микроорганизмы окислительных циклов серы и железа // Микробиология. 2006. Т. 75. №. 5. С. 593-629.

3. Кондратьева Т.Ф., Булаев А.Г., Муравьев М.И. Микроорганизмы в биотехнологиях переработки сульфидных руд. М.: Наука, 2015. 212 c.

4. Припачкин П.В. и др. Cu-Ni-ЭПГ и Сr месторождения Мончегорского района, Кольский п-ов, Россия // Путеводитель геологической экскурсии. Апатиты: ГИ КНЦ РАН. 2013.

5. Чижиков Д.М., Гуляницкая З.Ф., Гурович Н.А., Китлер И.Н. Гидрометаллургия сульфидных сплавов и штейнов. М.: ИАН СССР, 1962.

6. Anjum F., Shahid M., Akcil A. Biohydrometallurgy techniques of low grade ores: A review on black shale // Hydrometallurgy. 2012. 117. P. 1-12.

7. Baker B. J., Banfield J. F. Microbial communities in acid mine drainage // FEMS microbiology ecology. 2003. 44(2). P. 139-152.

8. Belzile N. et al. A review on pyrrhotite oxidation // Journal of Geochemical Exploration. 2004. 84(2). P. 65-76.

9. Brierley J. A., Brierley C. L. Present and future commercial applications of biohydrometallurgy // Hydrometallurgy. 2001. 59(2-3). P. 233-239.

10. Cameron R. A. et al. Bioleaching of six nickel sulphide ores with differing mineralogies in stirred-tank reactors at $30 \mathrm{C} / /$ Minerals Engineering. 2013. 49. P. 172-183.

11. Colmer A. R., Hinkle M. E. The role of microorganisms in acid mine drainage: a preliminary report // Science. 1947. 106(2751). P. 253-256.

12. Debernardi G., Carlesi C. Chemical-electrochemical approaches to the study passivation of chalcopyrite // Mineral Processing and Extractive Metallurgy Review. 2013. 34(1). P. 10-41.

13. Donati E. R., Sand W. (ed.). Microbial processing of metal sulfides. Springer Science \& Business Media, 2007.

14. Dutrizac J. E. Factors affecting alkali jarosite precipitation // Metallurgical Transactions B. 1983. 14(4). P. 531-539.

15. Fu B. et al. Bioleaching of chalcopyrite by pure and mixed cultures of Acidithiobacillus spp. and Leptospirillum ferriphilum // International Biodeterioration \& Biodegradation. 2008. 62(2). P. 109-115.

16. Garcia, O., Bigham, J.M., Moretto, R., Tuovinen, O.H., 1997. Products of oxidative dissolution of a complex sulfide mineral system by Thiobacillus ferrooxidans and Thiobacillus thiooxidans // Proceedings IBS '97 - Biomine '97 (Sydney). Australian Mineral Foundation, Glenside, pp. M7.2.1-M7.2.9.

17. Garg S. et al. Bioleaching of pyrrhotite tailings for Ni extraction-insights into an adaptive evolution study // MetSoc of CIM Proceedings of the 54th Annual Conference of Metallurgists (COM 2015). 2015.

18. Giaveno A., Donati E. Bioleaching of heazelwoodite by Thiobacillus spp // Process Biochemistry. 2001. 36(10). P. 955-962.

19. Gu G. et al. Effects of Leptospirillum ferriphilum and Acidithiobacillus caldus on surface properties of pyrrhotite // Hydrometallurgy. 2009. 100(1-2). P. 72-75.

20. Gu G., Hu K., Li S. Surface characterization of chalcopyrite interacting with Leptospirillum ferriphilum // Transactions of Nonferrous Metals Society of China. 2014. 24(6). P. 1898-1904.

21. Hackl R. P. et al. Passivation of chalcopyrite during oxidative leaching in sulfate media // Hydrometallurgy. 1995. 39(1-3). P. 25-48.

22. Hallberg K. B., Johnson D. B. Novel acidophiles isolated from moderately acidic mine drainage waters // Hydrometallurgy. 2003. 71(1-2). P. 139-148. 
23. Harlamovs J.R. et al. Heap bioleaching process for the extraction of zinc: Patent No. 6736877. США. 2004.

24. Kai T., Nishi M., Takahashi T. Adaptation of Thiobacillus ferrooxidans to nickel ion and bacterial oxidation of nickel sulfide // Biotechnology letters. 1995. 17(2). P. 229-232.

25. Ke J., Li H. Bacterial leaching of nickel-bearing pyrrhotite // Hydrometallurgy. 2006. 82(3-4). P. $172-175$.

26. Klauber C. A critical review of the surface chemistry of acidic ferric sulphate dissolution of chalcopyrite with regards to hindered dissolution // International Journal of Mineral Processing. 2008. 86(1-4). P. 1-17.

27. LI H., Chao L. I., Zhang Z. Decomposition mechanism of pentlandite during electrochemical bio-oxidation process // Transactions of Nonferrous Metals Society of China. 2012. 22(3). P. 731-739.

28. Mason L. J., Rice N. M. The adaptation of Thiobacillus ferrooxidans for the treatment of nickel-iron sulphide concentrates // Minerals Engineering. 2002. 15(11). P. 795-808.

29. Pagnanelli F. et al. Use of natural materials for the inhibition of iron oxidizing bacteria involved in the generation of acid mine drainage // Hydrometallurgy. 2007. 87(1-2). P. 27-35.

30. Panda S. et al. Insights into heap bioleaching of low grade chalcopyrite ores - A pilot scale study // Hydrometallurgy. 2012. 125. P. 157-165.

31. Plumb J. J., Muddle R., Franzmann P. D. Effect of $\mathrm{pH}$ on rates of iron and sulfur oxidation by bioleaching organisms // Minerals Engineering. 2008. 21(1). P. 76-82.

32. Pradhan N. et al. Heap bioleaching of chalcopyrite: a review // Minerals Engineering. 2008. 21(5). P. $355-365$.

33. Qiu Guanzhou, Qin Wenqing, Lan Zhuoyue. Elective culture of bioleaching on pyrrhotite // Transactions of Nonferrous Metal Society of China. 2003. 13(1). P. 175-179.

34. Rawlings D.E. Heavy metal mining using microbes //Annual Reviews in Microbiology. 2002. 56(1). P. 65-91.

35. Rodriguez Y. et al. New information on the chalcopyrite bioleaching mechanism at low and high temperature // Hydrometallurgy. 2003. 71(1-2). P. 47-56.

36. Rosenblum F., Spira P. Evaluation of hazard from self-heating of sulphide rock // International Journal of Rock Mechanics and Mining Sciences and Geomechanics Abstracts. 1995. 32(7). P. 350A-351A.

37. Salo-Zieman V.L.A., Kinnunen P.H.M., Puhakka J.A. Bioleaching of acid - consuming low - grade nickel ore with elemental sulfur addition and subsequent acid generation // Journal of Chemical Technology \& Biotechnology: International Research in Process, Environmental \& Clean Technology. 2006. 81(1). P. 34-40.

38. Santos L. R. G. et al. Bioleaching of a complex nickel-iron concentrate by mesophile bacteria // Minerals Engineering. 2006. 19(12). P. 1251-1258.

39. Sasaki K., Takatsugi K., Tuovinen O. H. Spectroscopic analysis of the bioleaching of chalcopyrite by Acidithiobacillus caldus // Hydrometallurgy. 2012. 127. P. 116-120.

40. Scharer J. M., Janzen M. P., Nicholson R. V. Pyrrhotite reaction kinetics: reaction rates for oxidation by oxygen, ferric iron, and for nonoxidative dissolution // Geochimica et Cosmochimica Acta. 2000. 64(9). P. 1511-1522.

41. Schippers A. et al. Biomining: metal recovery from ores with microorganisms // Geobiotechnology I. Springer, Berlin, Heidelberg, 2013. P. 1-47.

42. Schippers A. Microorganisms involved in bioleaching and nucleic acid-based molecular methods for their identification and quantification // Microbial processing of metal sulfides. Springer, Dordrecht, 2007. P. 3-33.

43. Semenza M. et al. The role of Acidithiobacillus caldus in the bioleaching of metal sulfides // Latin American applied research. 2002. 32(4). P. 303-306.

44. Stott M. B. et al. The role of iron-hydroxy precipitates in the passivation of chalcopyrite during bioleaching // Minerals Engineering. 2000. 13(10-11). P. 1117-1127.

45. Temple K. L., Colmer A. R. The autotrophic oxidation of iron by a new bacterium: Thiobacillus ferrooxidans // Journal of bacteriology. 1951. 62(5). P. 605.

46. Torma A. E. Microbiological oxidation of synthetic cobalt, nickel and zinc sulfides by Thiobacillus ferrooxidans // Revue canadienne de biologie. 1971. 30(3). P. 209.

47. Van Aswegen P. C., Van Niekerk J., Olivier W. The BIOX ${ }^{\mathrm{TM}}$ process for the treatment of refractory gold concentrates // Biomining. Springer, Berlin, Heidelberg, 2007. P. 1-33.

48. Veglio F. et al. Process development of pyrrhotite ore bio-oxidation for gold recovery cyanidation // T. Vargas, CA Jerez, JV Wiertz, \& H. Toledo, Biohydrometallurgy processing. Universidad de Chile, Santiago, Chile. 1995.

49. Vilcáez J., Suto K., Inoue C. Bioleaching of chalcopyrite with thermophiles: temperature-pH-ORP dependence // International Journal of Mineral Processing. 2008. 88(1-2). P. 37-44.

50. Watling H.R. The bioleaching of nickel-copper sulfides // Hydrometallurgy. 2008. 91(1-4). P. 70-88.

51. Watling H.R. The bioleaching of sulphide minerals with emphasis on copper sulphides - a review // Hydrometallurgy. 2006. 84(1-2). P. 81-108.

52. Williams T. BIOHEAPTM bacterial leaching of the Sherlock Bay Nickel Mine primary nickel-sulphide ore in saline water // Nickel/Cobalt Conference (Perth), ALTA Metallurgical Services, Melbourne. 2006. P. 13.

53. Zhang G., Fang Z. The contribution of direct and indirect actions in bioleaching of pentlandite // Hydrometallurgy. 2005. 80(1-2). P. 59-66.

54. Zhao H. et al. Electrochemical dissolution process of chalcopyrite in the presence of mesophilic microorganisms // Minerals Engineering. 2015. 71. P. 159-69. 